\title{
Consuming insects: are there health benefits?
}

\author{
N. Roos ${ }^{1}$ and A. van Huis ${ }^{2 *}$ \\ ${ }^{1}$ Department of Nutrition, Exercise and Sports, University of Copenhagen, Rolighedsvej 26, 1958 Frederiksberg C, Denmark; \\ ${ }^{2}$ Laboratory of Entomology, Wageningen University and Research Centre, P.O. Box 16, 6700 AA Wageningen, the Netherlands; \\ editor-in-chief@insectsasfoodandfeed.com
}

How healthy are insects? This is a highly relevant question in view of the global interest in the potential of insects as a sustainable food source in food systems and diets. Edible insects, like other foods, can provide nutrients and dietary energy to meet the requirements of the human body as a part of a varied diet. They also have the potential to provide bioactive compounds that have health benefits beyond simple nutritional values, as is the case for other food groups such as fruits and vegetables. Various recent studies have indicated such bioactivity in different insect species. The enormous number of edible insect species may be a source of novel bioactive compounds with health benefits addressing global health challenges. However, any identified health benefits need to be confirmed in human studies or in standardised assays accepted in health research prior to making health claims.

\section{Health challenges}

Populations all over the world are being challenged by nutrition and health problems. Worldwide, more than 150 million pre-school children are stunted (short for their age) due to poor diets and livelihood. The annual deaths of more than 3 million young children are caused by undernutrition, either directly by lack of sufficient food or by lack of the required micronutrients in the diet (Black et al., 2013).

In addition, modern lifestyles across populations - in highincome as well as low- and middle-income countries - have led to a sharp increase in the burdens of lifestyle-related health risks such as obesity and high blood pressure, and the related occurrence of non-communicable diseases (NCD) such as cardiovascular diseases, cancer and diabetes. WHO estimates that NCD cause 16 million deaths every year (WHO, 2015).

The prevalence of micronutrient deficiency, also known as 'hidden hunger', affects more than 2 billion people (IFPRI, 2016), for whom a lack of iron and zinc in particular is a major problem in low-income countries, contributing to multiple disorders including anaemia and stunted growth (Black et al., 2013). Iron and zinc deficiencies are mainly due to the dominance of plant-based diets, in which not only are iron and zinc levels low, but the bioavailability can also be very low due to mineral binding phytic acid (Saini et al., 2016). Iron and zinc are particular bioavailable from animal-source foods, which makes it relevant to consider edible insects as a means of improving the quality of diets.

\section{Nutritional value of edible insects}

The nutritional composition of edible insects is difficult to generalise, given that more than 2,100 different species are eaten (Jongema, 2017). However, edible insects can essentially be viewed as an animal-source food - like meat, fish, eggs and milk - which can contribute valuable protein, fat and important micronutrients to humans as a part of a varied diet.

The protein quality of insects is generally high in terms of providing essential amino acids (Rumpold and Schlüter, 2013). To fully document the protein quality, more studies of the digestibility of protein are needed, using in vivo methods standardised for the evaluation of digestibility in humans (Lee et al., 2016). The nutritional quality of fat, in terms of the composition of the fatty acids, is highly variable between insect species and also changes depending on what the insects have eaten (Finke and Oonincx, 2017); this is shown in a feeding study by Lehtovaara et al. (2017) published in this volume. Generally, fat in insects is characterised as comparable to fat in poultry and fish, but likely to contain more of the desired unsaturated fatty acids, either monounsaturated or the more healthy polyunsaturated fatty acids (PUFA) (Rumpold and Schlüter, 
2013). However, the long-chained PUFAs present in marine fish (docosahexaenoic acid and eicosapentaenoic acid) have rarely been detected in insects.

Many insect species contain high levels of iron and zinc as reviewed by (Rumpold and Schlüter, 2013), though this is highly variable between samples. In Africa, in particular the mopane caterpillar Imbrasia belina (Payne et al., 2015) and various species of termites (Kinyuru et al., 2013) contain high levels of these minerals. In vitro studies of the bioavailability of zinc and iron in grasshoppers, crickets, and mealworms have shown promising results, but also variation between the species (Latunde-Dada et al., 2016). However, since the absorption of iron in humans is particularly complex (Hurrell and Egli, 2010) and since iron compounds found in insects are quite different from those found in vertebrates (Pham and Winzerling, 2010), an assessment of the bioavailability in human studies is required to fully evaluate the nutritional value of various edible insects for these important minerals.

The establishment of solid scientific evidence of the nutritional composition of edible insects requires systematic studies of contents and variation of each of the relevant nutrients. The INFOODS programme at Food and Agriculture Organization (FAO) in Rome has published the 'Food composition database for biodiversity' with the aim of making nutritional values of wild and underutilised foods available (Charrondière et al., 2013). In the 2017 version 4.0 of this database, a total of 471 entries of edible insects (covering different insect species and various preparation methods) were included (FAO, 2017). However, the variation in nutrient composition in data derived from different studies is high, caused by true variation between insects collected from different environments or the rearing conditions (Finke and Oonincx, 2014), but also caused by the type of analytical method used (Payne et al., 2016). Studies on nutritional composition of edible insects should meet standards to be included in international food composition databases (Nowak et al., 2014). Processing and conservation methods also need to be considered (Ekpo, 2011; Kinyuru et al., 2010; Madibela et al., 2007).

\section{Bioactivity - what is the evidence?}

Besides being a source of valuable nutrients, studies have found bioactive compounds in insects with characteristics that could have the potential to reduce health risks and strengthen the immune system. As with bioactive compounds identified in other foods, health benefits needs to be sufficiently documented to be claimed, and studies directly in humans are generally a prerequisite. More research into the impact of potentially bioactive compounds identified in insects on human health is required.

\section{Antioxidants}

Several studies have reported antioxidant activity in insect species (Dutta et al., 2016; Zielińska et al., 2016). Antioxidants, in principle, have the potential to prevent molecular damage in the human body, and foods rich in antioxidants have been considered potentially beneficial in the prevention of cardiovascular and other diseases. However, the evidence that antioxidant activity in foods translates directly into a positive health impact in humans is weak, primarily because the activity is likely to change during the digestive and metabolic processes. The European Food Safety Authority (EFSA) has revisited its guidelines this year (EFSA, 2017), and reconfirmed that antioxidants needs to be assessed in vivo in humans to be claimed beneficial. This will also apply to edible insects.

\section{Hypertension}

High blood pressure is one of the leading preventable risk factors for premature death and disability worldwide, affecting up to one third of the world's population (Mills et al., 2016). Angiotensin is a peptide hormone that causes vasoconstriction and a subsequent increase in blood pressure. An enzyme converts the hormone angiotensin I to the active vasoconstrictor angiotensin II. As a result, the angiotensin-converting enzyme (ACE) causes blood vessels to constrict, which is why ACE inhibitors are used as pharmaceutical drugs for the treatment of cardiovascular diseases. ACE inhibitory activity is widely distributed in mammalian tissues, and has also been identified in a number of insects as reviewed by Cito et al. (2017) in this volume. Species such as wax moth Galleria mellonella, the yellow mealworm Tenebrio molitor and the silkworm Bombyx mori have been found to have levels of ACE inhibitory activity comparable with other food sources. As highlighted by Cito et al. (2017), the ACE inhibitory peptides identified in insects still need to be assessed in vivo in human studies or assays accepted in health research for their actual capacity to reduce blood pressure. Peptides with high in vitro activity may be metabolised to peptides with lesser or no antihypertensive in vivo effects - or to peptides with higher inhibitory activity.

\section{Obesity and type 2 diabetes}

Obesity and overweight is a leading preventable cause of death worldwide. In 2015, 600 million adults and 100 million children were obese and overweight, and obesity caused 4 million deaths (The GBD Obesity Collaborators, 2017). One of the health consequences of overweight and obesity is an increased risk of NCDs such as type 2 diabetes. In 2013, close to 400 million people had diabetes; this number is expected to rise to about 600 million by 2035 (Guariguata et al., 2014). While lifestyle change is the primary approach to weight control, there are also pharmacological agents 
identified that can help weight loss through different physiological pathways (Tonstad et al., 2016). At present, there are no such agents identified in edible insects that have been tested in humans. Studies in mice models have indicated bioactive compounds in insects, which may be effective in weight control. A study by Seo et al. (2017) showed that the daily intake of yellow mealworm larvae powder by obese mice attenuated body weight gain by reducing lipid accumulation and triglyceride content in adipocytes, thus indicating the potential of a bioactive compound to induce weight loss. Another pathway of bioactivity investigated entails a reduction in endoplasmic reticulum (ER) stress. ER is a cellular condition found in obese as well as type 2 diabetes patients causing a function failure of cells, including insulin-producing beta cells (Laybutt et al., 2007). A study by Kim et al. (2016) found ER stress-reducing effects as well as hormone-induced change in feeding behaviour of an ethanol extract of the Korean horn beetle Allomyrina dichotoma when injected into the brain tissue of obese mice. However, such findings in animal models of potential bioactivity of interest for human health need to be confirmed in human studies.

\section{Chitin and immunity}

Chitin, a primary component of the exoskeletons of arthropods, represents the second-most abundant polysaccharide in nature, after cellulose. Humans do not synthetise chitin. Therefore, chitin-containing protozoa, fungi, arthropods, and nematodes are targeted for recognition by the immune system. Chitin and its degradation products are sensed primarily in the lungs or gut, where it activates a variety of innate and adaptive immune cells. Chitin induces cytokine production, recruits leukocytes, and activates macrophages (Elieh Ali Komi et al., in press). Chitin can be degraded by chitinases identified in the human digestive fluid (Paoletti et al., 2007). The function of chitinases is not only to catalyse the hydrolysis of chitin-producing pathogens, but seems to include a crucial role in bacterial infections and inflammatory diseases (Di Rosa et al., 2016). They may in future be utilised as diagnostic and prognostic markers for numerous diseases.

\section{Vitamin B12}

Cobalamin - or vitamin B12 - is synthesised by certain bacteria and algae and accumulates in meat, milk and other animal-source food, as the only natural food source of vitamin B12 for humans. Vitamin B12 plays a key role in the functioning of the brain and nervous system and in the formation of red blood cells. Few insects have been analysed for vitamin B12. The FAO/INFOOD database on biodiversity includes vitamin B12 for only a few species, among them house cricket Acheta domesticus, yellow mealworm T. molitor, wax moth G. mellonella, and silkworm B. mori (FAO, 2017). The contents range from less than $0.5 \mu \mathrm{g} / 100$ fresh weight in mealworm and silkworm, to more than $8 \mu \mathrm{g} / 100 \mathrm{~g}$ fresh weight in house cricket. The daily recommended intake is $2.4 \mu \mathrm{g} /$ day (FAO/WHO, 2004; p. 284), indicating in particular crickets as a promising source of vitamin B12. More species need to be analysed following standards for inclusion in food composition tables (Novak et al., 2014).

\section{Parkinson's disease and silkworm}

Parkinson's disease affects 6 million people each year, resulting in more than 100,000 deaths each year. Nguyen $e t$ al. (2016) found that when boiled and freeze-dried powder of the silk worm B. mori was fed to Drosophila flies, lifespan increased, while symptoms of rotenone-induced Parkinson's disease were reduced. More research is needed to find out how such insect-to-insect bioactivity can transfer to effects in humans.

\section{Risks of negative health impacts}

While the search for bioactive compounds in insects to support health is driven by the positive agenda of improving human life, research must also address any health risks related to the consumption of insects. For example, cyanogenic compounds were identified in the edible beetle Eulepida mashona in Zimbabwe, and even though the compounds were degraded by heating in traditional cooking practices, caution was advised, e.g. when feeding the insects to small children (Musundire et al., 2016). Insects - farmed or wild - should be considered for the risk of accumulation of any toxic compounds.

\section{Conclusions}

Insects share the nutritional benefits of animal-source foods and can provide valuable nutrients as a part of a varied diet. Nutrient analysis of insects should follow international recognised standard procedures for being accepted to be included in food composition databases to make such data more accessible to consumers. Edible insect species may be a source of novel bioactive compounds addressing the enormous global health challenges in low- as well as high-income countries. However, any indication of health benefits needs to be confirmed in human studies or in standardised assays accepted in health research prior to be claimed.

\section{References}

Black, R.E., Victora, C.G., Walker, S.P., Bhutta, Z.A., Christian, P., de Onis, M., Ezzati, M., Grantham-McGregor, S., Katz, J., Martorell, R. and Uauy, R., 2013. Maternal and child undernutrition and overweight in low-income and middle-income countries. The Lancet 382: 427-451. 
Charrondière, R.U., Stadlmayr, B., Rittenschober, D., Mouille, B., Nilsson, E., Medhammar, E., Olango, T., Eisenwagen, S., Persijn, D., Ebanks, K., Nowak, V., Du, J. and Burlingame, B., 2013. FAO/ INFOODS food composition database for biodiversity. Food Chemistry 140: 408-412.

Cito, A., Botta, M., Francardi, V. and Dreassi, E., 2017. Insects as source of angiotensin converting enzyme inhibitory peptides. Journal of Insects as Food and Feed 3: 231-240.

Di Rosa, M., Distefano, G., Zorena, K. and Malaguarnera, L., 2016. Chitinases and immunity: ancestral molecules with new functions. Immunobiology 221: 399-411.

Dutta, P., Dey, T., Manna, P. and Kalita, J., 2016. Antioxidant potential of Vespa affinis L., a traditional edible insect species of North East India. PLoS ONE 11: e0156107.

Ekpo, K.E., 2011. Effect of processing on the protein quality of four popular insects consumed in southern Nigeria. Archives of Applied Science Research 3: 307-326.

Elieh Ali Komi, D., Sharma, L. and Dela Cruz, C.S., in press. Chitin and its effects on inflammatory and immune responses. Clinical Reviews in Allergy \& Immunology, https://doi.org/10.1007/s12016017-8600-0.

European Food Safety Authority (EFSA), 2017. Draft guidance for the scientific requirements for health claims related to antioxidants, oxidative damage and cardiovascular health (Revision 1). EFSA Journal. Available at: https://www.efsa.europa.eu/sites/default/ files/engage/170712.pdf.

Finke, M.D. and Oonincx, D.G.A.B., 2014. Insects as food for insectivores. In: Juan Morales-Ramos, M.G.R. and Shapiro-Ilan, D. (eds.). Mass production of beneficial organisms. Academic Press, San Diego, CA, USA, pp. 583-616.

Finke, M.D. and Oonincx, D.G.A.B., 2017. Insects and nutrients. In Van Huis, A. and Tomberlin, J.K. (eds.). Insects as food and feed: from production to consumption. Wageningen Academic Publishers, Wageningen, the Netherlands, pp. 291-316.

Food and Agriculture Organization of the United Nations (FAO), 2017. FAO/INFOODS Food Composition Database for Biodiversity Version 4.0. FAO, Rome, Italy. Available at: http://www.fao.org/3/ai7364e.pdf.

Food and Agriculture Organization of the United Nations/World Health Organization (FAO/WHO), 2004. Vitamin and mineral requirements in human nutrition. In: Report of a joint FAO/WHO expert consultation, Bangkok, Thailand, 21-30 September 1998 ( $2^{\text {nd }}$ Ed.). WHO, Geneva, Switzerland. Available at: http://tinyurl. com/yav769jl.

Guariguata, L., Whiting, D.R., Hambleton, I., Beagley, J., Linnenkamp, U. and Shaw, J.E., 2014. Global estimates of diabetes prevalence for 2013 and projections for 2035. Diabetes Research and Clinical Practice 103: 137-149.

Hurrell, R. and Egli, I., 2010. Iron bioavailability and dietary reference values. The American Journal of Clinical Nutrition 91: 1461S-1467S.

International Food Policy Research Institute (IFPRI), 2016. Global nutrition report 2016: from promise to impact: ending malnutrition by 2030. IFPRI, Washington DC, USA. Available at: http://tinyurl. com/yc27u7kp.
Jongema, Y., 2017. List of edible insects of the world. Wageningen University \& Research, Wageningen, the Netherlands. Available at: http://tinyurl.com/mestm6p.

Kim, J., Yun, E.-Y., Park, S.-W., Goo, T.-W. and Seo, M., 2016. Allomyrina dichotoma larvae regulate food intake and body weight in high fat diet-induced obese mice through mTOR and Mapk signaling pathways. Nutrients 8: 100 .

Kinyuru, J.N., Kenji, G.M., Njoroge, S.M. and Ayieko, M., 2010. Effect of processing methods on the in vitro protein digestibility and vitamin content of edible winged termite (Macrotermes subhylanus) and grasshopper (Ruspolia differens). Food Bioprocess Technology 3: 778-782.

Kinyuru, J.N., Konyole, S.O., Roos, N., Onyango, C.A., Owino, V.O., Owuor, B.O., Estambale, B.B., Friis, H., Aagaard-Hansen, J. and Kenji, G.M., 2013. Nutrient composition of four species of winged termites consumed in western Kenya. Journal of Food Composition and Analysis 30: 120-124.

Latunde-Dada, G.O., Yang, W. and Vera Aviles, M., 2016. In vitro iron availability from insects and sirloin beef. Journal of Agricultural and Food Chemistry 64: 8420-8424.

Laybutt, D.R., Preston, A.M., Åkerfeldt, M.C., Kench, J.G., Busch, A.K., Biankin, A.V. and Biden, T.J., 2007. Endoplasmic reticulum stress contributes to beta cell apoptosis in type 2 diabetes. Diabetologia 50: 752-763.

Lee, W.T., Weisell, R., Albert, J., Tomé, D., Kurpad, A.V. and Uauy, R., 2016. Research approaches and methods for evaluating the protein quality of human foods proposed by an FAO expert working group in 2014. The Journal of Nutrition 146: 929-932.

Lehtovaara, V.J., Valtonen, A., Sorjonen, J., Hiltunen, M., Rutaro, K., Malinga, G.M., Nyeko, P. and Roininen, H., 2017. The fatty acid contents of the edible grasshopper Ruspolia differens can be manipulated using artificial diets. Journal of Insects as Food and Feed 3: 253-262.

Madibela, O.R., Seitiso, T.K., Thema, T.F. and Letso, M., 2007. Effect of traditional processing methods on chemical composition and in vitro true dry matter digestibility of the mophane worm (Imbrasia belina). Journal of Arid Environments 68: 492-500.

Mills, K.T., Bundy, J.D., Kelly, T.N., Reed, J.E., Kearney, P.M., Reynolds, K., Chen, J. and He, J., 2016. Global disparities of hypertension prevalence and control: a systematic analysis of population-based studies from 90 countries. Circulation 134: 441-450.

Musundire, R., Zvidzai, C.J., Chidewe, C., Ngadze, R.T., Macheka, L., Manditsera, F.A., Mubaiwa, J. and Masheka, A., 2016. Nutritional and bioactive compounds composition of Eulepida mashona, an edible beetle in Zimbabwe. Journal of Insects as Food and Feed 2: 179-187.

Nguyen, P., Kim, K.-Y., Kim, A.Y., Kim, N.-S., Kweon, H., Ji, S.-D. and Koh, Y.H., 2016. Increased healthspan and resistance to Parkinson's disease in Drosophila by boiled and freeze-dried mature silk worm larval powder. Journal of Asia-Pacific Entomology 19: 551-561.

Nowak, V., Persijn, D., Rittenschober, D. and Charrondière, U.R., 2014. Review of food composition data for edible insects. Food Chemistry 193: 39-46.

Paoletti, M.G., Norberto, L., Damini, R. and Musumeci, S., 2007. Human gastric juice contains chitinase that can degrade chitin. Annals of Nutrition and Metabolism 51: 244-251. 
Payne, C.L.R., Scarborough, P., Rayner, M. and Nonaka, K., 2016. A systematic review of nutrient composition data available for twelve commercially available edible insects, and comparison with reference values. Trends in Food Science \& Technology 47: 69-77.

Payne, C.L.R., Umemura, M., Dube, S., Azuma, A., Takenaka, C. and Nonaka, K., 2015. The mineral composition of five insects as sold for human consumption in Southern Africa. African Journal of Biotechnology 14: 2443-2448.

Pham, D.Q.D. and Winzerling, J.J., 2010. Insect ferritins: typical or atypical? Biochimica et Biophysica Acta (BBA) - General Subjects 1800: 824-833.

Rumpold, B.A. and Schlüter, O.K., 2013. Nutritional composition and safety aspects of edible insects. Molecular Nutrition \& Food Research 57: 802-823.

Saini, R.K., Nile, S.H. and Keum, Y.-S., 2016. Food science and technology for management of iron deficiency in humans: a review. Trends in Food Science \& Technology 53: 13-22.
Seo, M., Goo, T.-W., Chung, M., Baek, M., Hwang, J.-S., Kim, M.-A. and Yun, E.-Y., 2017. Tenebrio molitor larvae inhibit adipogenesis through AMPK and MAPKs signaling in 3t3-11 adipocytes and obesity in high-fat diet-induced obese mice. International Journal of Molecular Sciences 18: 518.

The GBD Obesity Collaborators, 2017. Health effects of overweight and obesity in 195 countries over 25 years. New England Journal of Medicine 377: 13-27.

Tonstad, S., Rössner, S., Rissanen, A. and Astrup, A., 2016. Medical management of obesity in Scandinavia 2016. Obesity Medicine 1: 38-44.

World Health Organization (WHO), 2015. Global status report on noncommunicable diseases 2014. WHO, Geneva, Switzerland. Available at: http://tinyurl.com/pgwxcpo.

Zielińska, E., Karaś, M. and Jakubczyk, A., 2016. Antioxidant activity of predigested protein obtained from a range of farmed edible insects. International Journal of Food Science \& Technology 52: 306-312. 
